FM3:

Scholarly Publication in Astronomy:

Evolution or Revolution? 


\title{
Evolution of Scholarly Publishing and Library Services in Astronomy Its Impact, Challenges, and Opportunities
}

\author{
Hema Wesley ${ }^{1}$ and Geetha Sheshadri ${ }^{2}$ \\ ${ }^{1}$ Consultant Editor, Indian Academy of Sciences, Bangalore, India \\ email: ruthwes09@gmail.com \\ ${ }^{2}$ Assistant Librarian, Raman Research Institute, Bangalore, India \\ email: geetha.sheshadri@gmail.com
}

\begin{abstract}
Scholarly publishing and its procedures have evolved rapidly, forcefully, and incredibly. Technical advances in the production and promotion of science content have dramatically augmented the visibility and reach, deepened the impact and intensified the thrust of science journal content. These changes range from checking text on perforated tapes to pit stop; from hot metal types to CTP; and from Gutenberg to colour digital printers. Intrinsic and inextricable to this revolutionary aspect of evolution in scholarly publishing is the evolution of library services in astronomy which catapulted library resources from preprints on shelves to customised digital repositories and from communicating observational data through postal telegrams to Tablets. What impact does this unique blend of revolutionary advances have on science and society, what are the consequent challenges, and what are the opportunities that can metamorphose from challenges inherent in the power and potential of the 'published word'?

The perspectives expressed in this paper stem from learning experiences of the authors at the Indian Academy of Sciences, publishers of ten science journals including the Journal of Astrophysics and Astronomy, and at the Raman Research Institute Library (in which Astronomy is one of the core subjects for research)
\end{abstract}

Keywords. Publishing, library services, evolution

\section{Introduction}

Publishing - the process of production and dissemination of information - is one of the metrics of scientific careers. 350 or so years ago the scientific journal was itself an innovation. This was in large part enabled by the emergence of the printing press: the Gutenberg Letter Press invented in the 15th century. While electronic publishing methods have resulted in rapid publication and wider dissemination, it, nevertheless, is also true that with speed and ease of automation, quality is to be ferociously guarded. Could traditional methods, when juxtaposed with the continuous onslaught of newer technologies in our publishing procedures, be the answer? Are people still the quintessential element in technology?

Why do we publish? The phrase "Publish or Perish" has itself, interestingly, evolved in its meaning. "Publish or perish" is a phrase coined to describe the pressure in academia to rapidly and continually publish academic work to sustain or further one's career. I see evolution in this very phrase which first appeared in a non-academic context in 1932 and became the buzz word for researchers about 30 years ago. It is now a software program that retrieves and analyses academic citations. 


\section{Impact of evolutionary developments}

How have publishing procedures evolved through the years; what is the impact of these developments; what are the challenges and opportunities for scholarly publishers in this digital age? How do we cope with and pre-empt the abuse and distortion of internet data, and with unethical practices that threaten to cripple the peer review system, and jeopardize publishing ethics and academic integrity? How can publishers fulfil their responsibility to publish content that is explicitly original?

Juxtaposed to this is the scenario in library services with increasing demand for eversions of journals and other e-resources and the gradual loss of value for printed journals. Librarians are developing and maintaining electronic libraries and vast digital resources combined with additional features of e-publishing, such as tools, voice, graphic arts, films, videos, CDs, DVDs, etc.

How can we prepare for the future of publishing or is it already here with the popularity of pre-print servers? How have publishers responded to the Open Access model while being aware that "the price of keeping something free comes with a cost"? Would this cost entail ensuring quality of the presentation and reliability of information? Are potential authors confused identifying traditional peer reviewed content, predatory journals, fake reviewers, depositing research in institutional repositories, copyrights and licences? Are libraries impacted by these developments?

\section{Publishing procedures}

Publishing procedures have evolved from traditional methods involving manual operations to advanced software (Fig. 1).

\section{Challenges and opportunities}

Reviewers play an essential part in research and scholarly publishing. Most academic publishing companies rely on effective peer-review processes to uphold the quality and validity of individual articles and the overall integrity of the journals. Editors are looking for original and innovative research. The peer review practice involves reviewers who are qualified to assess the significance of the research and comment on the content, methodology of the experiment, and the results. Publishers now use online submission and review management software through which authors can submit and track the processing of their article submissions. The software enables authors, reviewers, editorial board members, chief editors, and the editorial staff to interact within their subscribed domains to achieve the double blind peer review process.

There is, however, a flipside to this advanced technology — we are often confronted with duplicate submissions of MSS, multiple submissions to the same journal with different combinations of co-authors, withdrawal of papers midstream in the review cycle, coauthors submitting the same MS to another journal, and additions, deletions, and even changes in the order of author names. There are also authors who continue to commit fraudulent submissions even after publishers have imposed a ban on them.

The major forms of scientific misconduct are captured by three words: fabrication, falsification and plagiarism. Plagiarism jeopardizes careers and is unfair to the authors whose work they are stealing. The online tool Cross Check, endorsed by publishers worldwide, compares text with a database of millions of articles. If an article that includes plagiarized content has been published it has to be retracted. However, the article will still be shown on the website along with the reason for retraction. This ensures the 


\section{EVOLUTION OF PUBLISHING PROCEDURES}

Then
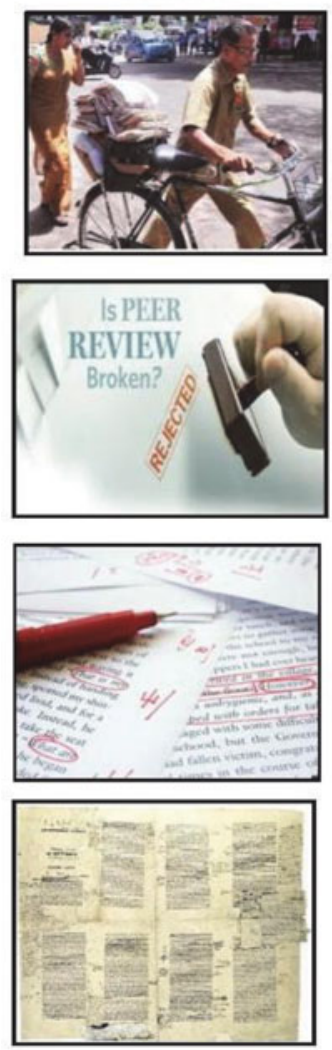

\begin{tabular}{|ll|}
\hline capitalize & underline \\
Decapitalize & striketort \\
insertfext & Jeenter[ \\
delete aqletter & Afinsert paragraph \\
transpode & Circtospell out \\
\hline
\end{tabular}
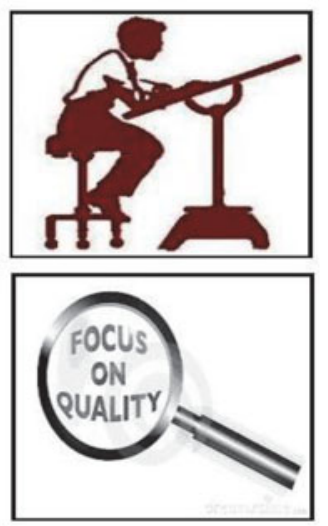
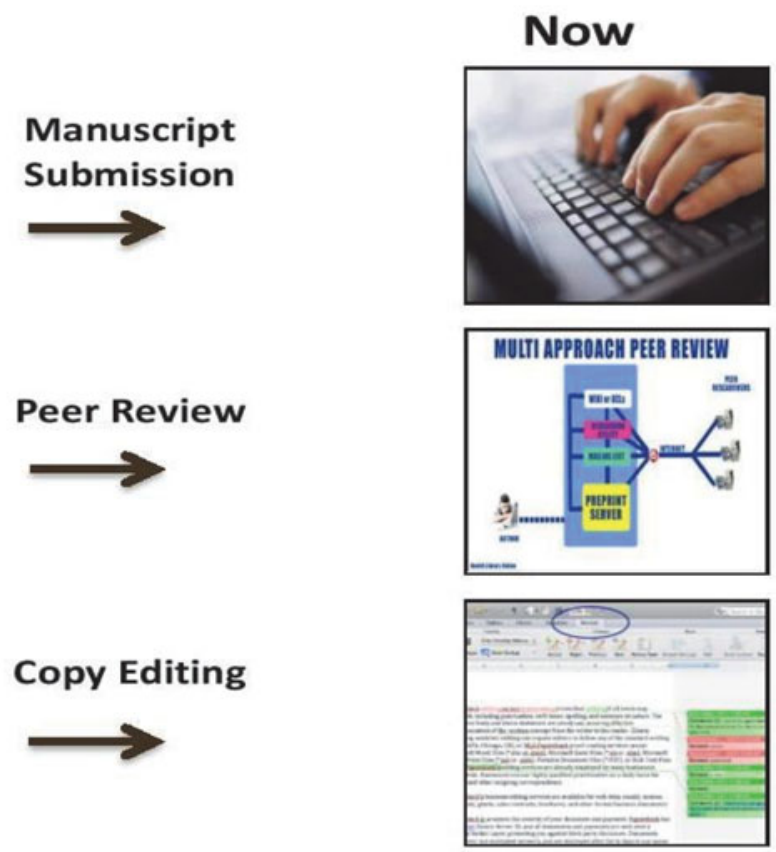

Formatting
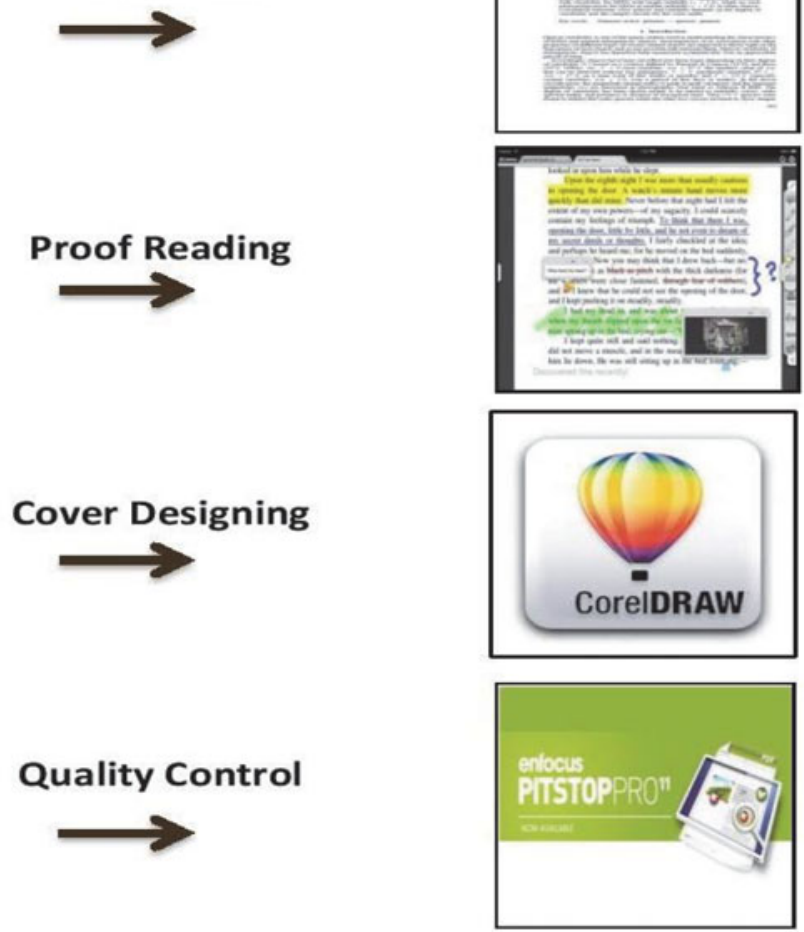

Figure 1. 
EVOLUTION OF PUBLISHING PROCEDURES (contd.)

Then
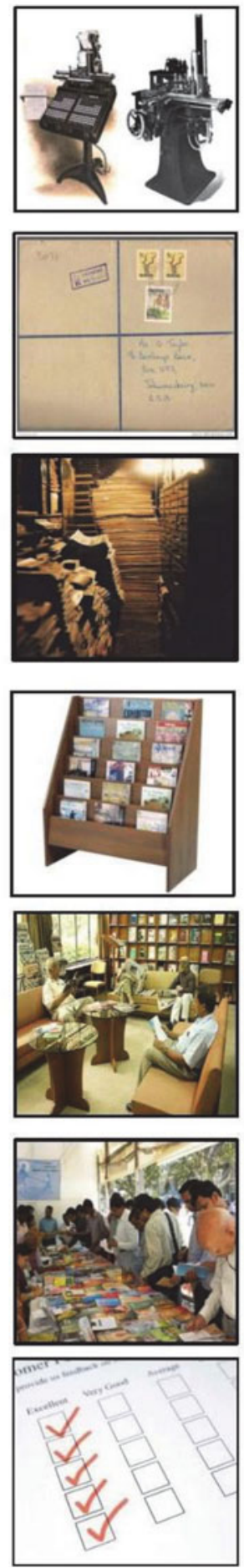

Now

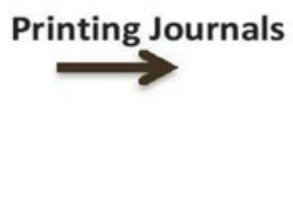

Dispatching
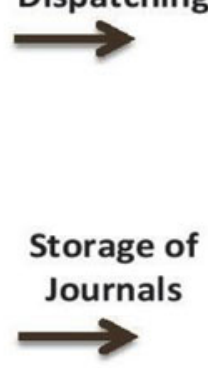

Display/Exhibition of Journals in library

Readers in Library
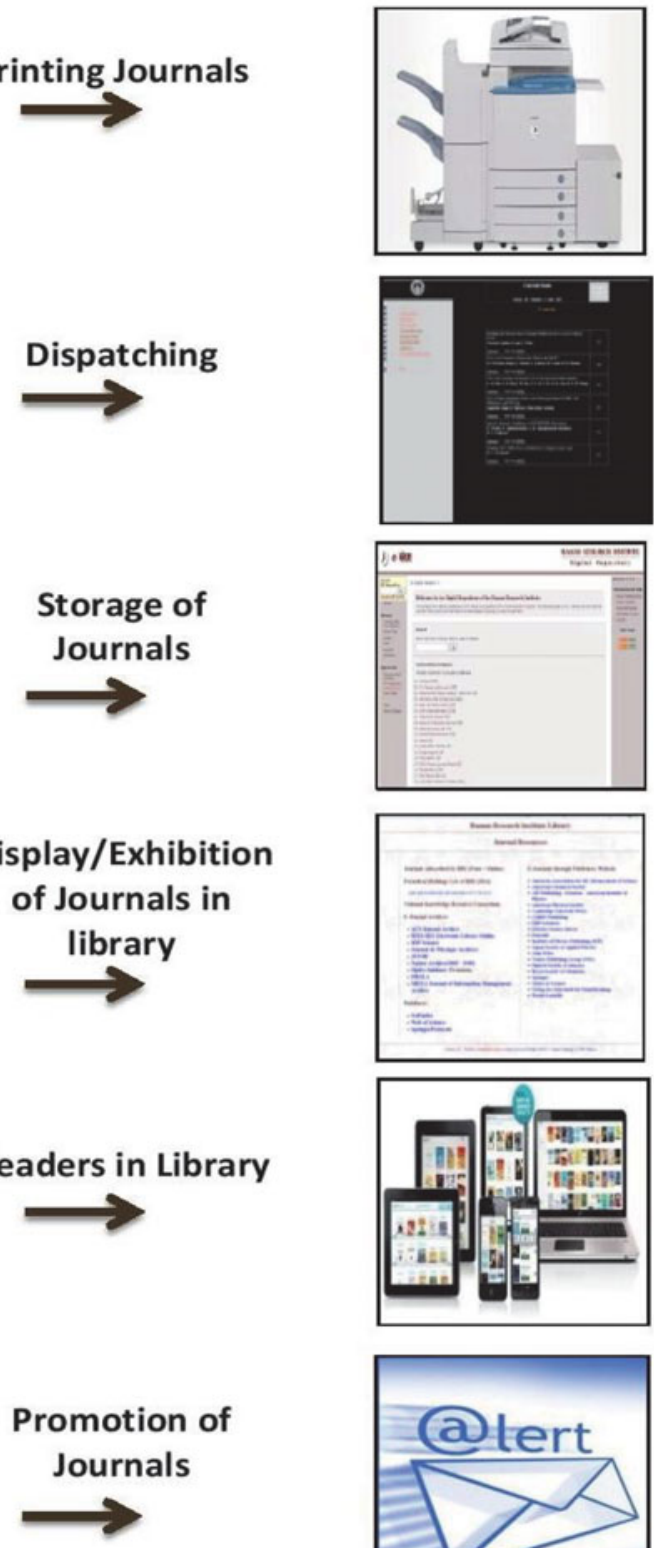

Success Assessment
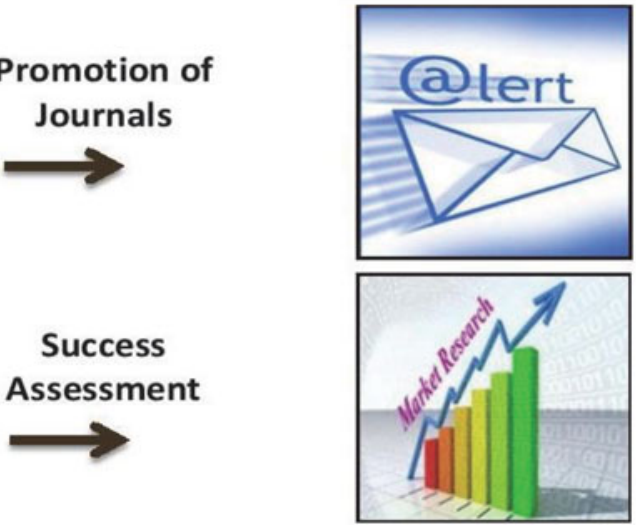

Figure 1. cont. 
plagiarism and researchers responsible are highlighted. Publishers cope with misconduct through steps to detect plagiarism, deal with established cases, and find ways to preempt such cases.

Among the activities undertaken by the Indian Academy of Sciences to promote and disseminate science, publications have occupied pride of place. The first issue of the Academy's earliest publication titled 'Academy Proceedings', a monthly, appeared in July 1934, the same month that the Academy was founded by Sir C. V. Raman. Publication of science journals has since remained an important activity. Today the Academy publishes 10 science journals in various disciplines. Since 2007 the Academy journals are co-published with Springer. Submissions to JAA and other Academy journals are processed through an online submission and review management system. Papers undergo a blind peer review procedure. Springer provides access to our journals? content worldwide in an online full text database on Springerlink. Free access to all Academy journals worldwide is provided via the website of the Indian Academy of Sciences.

Today's technology has placed our journals' content on the world stage and we now deal with factors and features such as downloads, impact factor, citations, online subscribers, consortia packages, online deals, citation analysis, market surveys, sales incentives, marketing strategies, and the need to secure data. Our journals have reached new and previously unimagined geographical areas. Downloads from our archives date back to 1948 !! Nevertheless, it is true that with speed, ease and automation of processes, quality must be ferociously guarded. This can be achieved by adopting technology, adapting it to our requirements and, most importantly, not compromising on the importance of trained and knowledgeable human interface which we believe is still the quintessential element in all technology.

The effectiveness of a personalized reminder email to reviewers and authors, in a particular instance perhaps, would outweigh an impersonal, automated letter. A dedicated proof reader's eye sees subtle inconsistencies missed by the machine and detect new mistakes in an otherwise correct piece of text unwittingly caused during conversion of files. A capable copyeditor's instinct is to catch the nuances of language expression. The indomitable spirit of the editorial staff ensures the accuracy of the most minute discrepancies such as position of an accent (tilde) on a letter, the distinguishing characteristic between an italic lower case 'v' and the Greek 'nu', the letters "fi" as a ligature, the minute difference between a minus sign and an en dash, the inbuilt space on either side of mathematical symbols, detect display equations in either TeX or Times Maths, or to look at a final proof and check by scanning it with an experienced eye for the finer aspects of formatting - symmetry, alignment, spacing, alliteration, hyphenation, layout, elegance, and clarity - before the page is passed for printing. An individual's skills vis-à-vis quality control, we have learned, can complement the limitations of automated processes and is therefore, to us, the imperative to achieve error free and well - produced publications in content, format and style.

\section{The future of publishing}

What then are the challenges and opportunities for publishers in the digital future? How has the evolution of scholarly publishing impacted us and how has this evolution demonstrated itself? Here we enumerate the developmental changes impacting publishing; only time will provide the answers to these challenges.

- The 'serials crises' and demand for open access to government funded research; university libraries challenging publishers for raising journal prices (the 'cost of knowledge' 
debate, journal boycotts); the open access movement; birth and development of the ideas of gold and green OA publishing

- Publishers' responses to APC, OA and embargoes; allowing final accepted versions in author's Institutional Repositories; new OA journals by commercial publishers with $\mathrm{APC}$ as revenue models; fee-supported open access to papers in non-OA journals for authors who are willing to pay

- Journal pricing schemes; growth of online subscriptions; site licensing; journal bundling; archive packages; back volume pricing; issues concerning perpetual license; concessional pricing for developing countries; consortium pricing; price negotiations

- Evolution of the definition of OA itself; copyright and licenses for use of published papers and data; Creative Commons licenses; publisher-allowed authors' rights; mandates imposed by research funding agencies to modify copyright transfer agreements; movement towards discouraging APC: the matter of 'affordability of OA'

- Publishing negative data on research to help researchers understand what NOT to do - will Editorial Boards accept this decision

- Identifying and investigating the trap of predatory journals

- Will books be subsumed by eBooks? "Books are important but they are not as good as reading" contrasted with "Libraries are the future of reading"

- The threat of self-publishing by authors

- Science societies losing control (to the commercialisation of research) of the editorial and quality processes and production of their journals

- 'Accepted Manuscript' and 'Version of Record' - which one should the author cite

- Transparency within the traditional and confidential peer review system

- There is need to incentivise good reviewers

- Technology keeping pace with threats to integrity and assisting readers and researchers with DOI, Crosscheck, Fundref, CrossMark, Retraction Watch and data repositories for data mining

- Is the future of publishing already here with the popularity of preprint servers new services that disrupt traditional publishing models?

How can publishers deal with the issues that confront them? Publishers, perhaps, will need to focus on adding value to content, such as explore newer formats, maintain a strong connect with authors, devise newer revenue models or develop multi-media platforms.

\section{Library Services}

How have library services evolved through the years and progressed to meet the requirements and demands of advanced technology? The focussed collection in any special library is at the core of its services and activities. Library service is the activity involved in information retrieval, delivery, maintenance, and preservation of its collection. The collection involves activities from acquisition of books, e-books and non-book materials; subscriptions to journals, e-journals, databases and maintaining perpetual access to open access books and journals to processing, maintaining and making information available to library users using both traditional methods (lending of books) as well as new emerging tools such as library web page and smart phones. Libraries are shifting focus from building local print collections to providing remotely accessed online resources to students and researchers and guiding their access needs through 'Federated search'.

The Raman Research Institute (RRI) Library has grown from the personal collection of the Nobel laureate Sir C. V. Raman into a modern library with print and electronic resources, an institutional repository, multimedia library and a partnership with National Knowledge Resource Consortium (NKRC) to access e-journals while affording internship 
training to students of library science from several universities. Astronomy is one of the core subjects for research at RRI; our dedicated focus is therefore on advancing methods and in proactive communication with astronomers, through forums such as LIS-FORUM, Forum for Resource sharing in Astronomy (FORSA) - custom made for astronomy libraries in India, NKRC, Astrolib and SLA-PAM.

LIBSYS - library management software used for library automation since 1994 has been updated with Libsys7 in 2015, which is a new web-based version with interactive features, customized federated search etc. The portals available on the RRI Library web page (http://www.rri.res.in/library.html) include: RRI Digital Repository, E-Books, EJournal Portal, Imprints Collection, Multimedia Library, Library OPAC (Online Public Access Catalogue ) and Open Access Portal.

\section{How library services have evolved at RRI}

Libraries have made constant transitions to become information centers that handle all types of knowledge, from paper to electronic media (CDs DVDs etc.), to networked resource (Figure 2).

\section{How have libraries responded to the demands of the scientific community?}

In the early 1980s, due to proliferation of information, library professionals working in the Institutes where astronomy was one of the main thrusts of research felt the need to come together and initiate a forum, which could act as a springboard for sharing and exchange of information. The first meeting of Astronomy librarians was held on July 29, 1981 at Raman Research Institute, Bangalore and informally launched Forum for Resource Sharing in Astronomy and Astrophysics (FORSA) with a vision and mission to share resources held in each library. Since 1989, FORSA members have met every year, in conjunction with the Annual Meeting of the Astronomical Society of India. At present, there are eleven institute members viz., ARIES, Bose Institute, CASA-OU, HRI, IIA, IUCAA, NCRA (TIFR), PRL, RRI, SINP and TIFR. The activities of FORSA are to facilitate access to journals/books and merged databases, access to websites of member institutions; actively participate in Resource Sharing; digitization of archival materials of the institute, and develop an open access Institutional Repository. Today, representatives of FORSA member institutions still maintain active informal interactions.

The NKRC, a national gateway of Science \& Technology On-line resources, established in 2009, is a network of libraries and information centres of 40 Council of Scientific and Industrial Research (CSIR) institutions and 28 Department of Science and Technology (DST) institutes. Today, NKRC facilitates access to 5,000+ e-journals of all major publishers, patents, standards, citation and bibliographic databases. Apart from licensed resources, NKRC is also a single point entity that provides users with access to a multitude of open access resources. Another extremely important objective of NKRC is to build the Institutional Repository platform of all research organizations based on a common standard using D-Space open source software and access from a single national window (http://nkrc.niscair.res.in/indexpage.php).

Library and Information Services in Astronomy (LISA) conferences held since 1988 include participants from the all parts of the world. LISA builds astronomy librarians? network and influences the professional life of astronomy librarians. Library staff of FORSA libraries especially RRI, IIA, IUCAA, NCRA - Pune, PRL, and TIFR have attended and contributed to LISA. LISA VI was organized by FORSA and co-hosted by 


\section{EVOLUTION OF LIBRARY SERVICES}

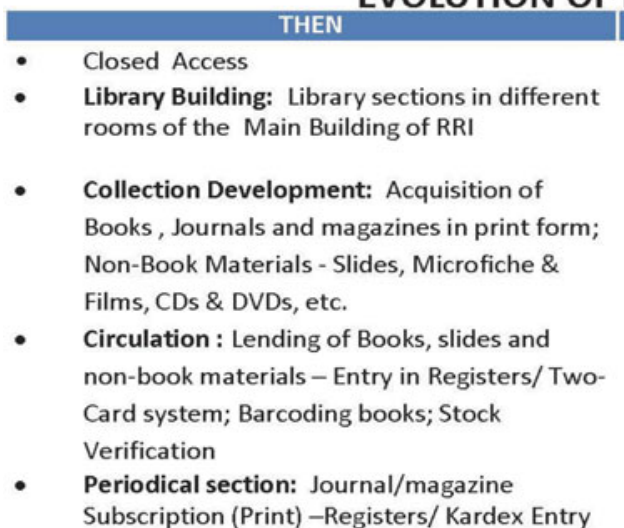

- Reference Service: Assistance in the use of the library including location of materials, use of the catalogs, Databases and the use of basic reference sources viz. almanacs, atlases

- Inter library loan: Document delivery by post/manual: books/magazines/journals Exchanged/borrowed between the groups of libraries in Bangalore

- Notice boards :Preprint services/Science News / Recent Additions of Journals and Books, etc.

- Photocopy services: Kores-stat and Xerox copies (Manual copiers); Reprography machines used

- Preservation \& Binding: Binding Journals; Reports, thesis; Repair of Books and Packing

- SDI services:

$\checkmark$ Compilation of Current awareness List \& Bibliographies

$\checkmark$ Astronomy lectures, talks etc. in Audio/Video Cassettes, CDs and DVDs

$\checkmark$ Preprints on shelves, memoirs of RRI publications of RRI (Print), Annual Reports etc.

$\checkmark$ Palomar sky survey charts were available as photographic prints till 1994, then as 102 CD

$\checkmark$ IAU Circulars received by post $\rightarrow$ Open Access

$\rightarrow$ Separate Library Building : Basement, Ground Floor and Mezzanine

$\rightarrow$ e-resources/ e-books/e-journals

$\rightarrow \quad$ Issue/Return through LIBSYS - Library Management Software \& Facilitating e-books via RRI homepage; Online Access /online Subscription

$\rightarrow \quad$ Entry through LIBSYS Software Access to E-journals from RRI webpage/ FORSA/NKRC Consortium

$\rightarrow$ Web OPAC facility to access library collection from anywhere anytime $(24 \times 7)$

$\rightarrow \quad$ Attending online queries In house and ILL- article Requests (soft copy) delivered via e-mail

$\rightarrow \quad$ Digital Display Board

$\rightarrow$ Facilitated with networked printers; Photocopying, scanning and converting to image/pdf and sent via email.

$\rightarrow$ Purchase of Online Archives; Binding Journals diminished; Reports, thesis; Repair of Books and other materials and Packing continues

$\rightarrow \quad$ Create lists using Online Databases -ADS \& WOS

$\rightarrow \quad$ Lectures, talks etc., access via Internet/ Repositories

$\rightarrow$ Placing preprints/articles online on arXive, Institutional Repositories, etc.

$\rightarrow$ Palomar sky survey charts are available Online, since 2001

$\rightarrow \quad$ IAU Circulars available On-line as IAUCS

Figure 2.

Inter-University Centre for Astronomy \& Astrophysics (IUCAA) Library and the National Centre for Radio Physics (NCRA) Library. Librarians, Astronomers, Computer Scientists, and Publishers met to discuss information maintenance and retrieval, new techniques and technologies, and the future of astronomy libraries and librarianship.

\section{Challenges and opportunities for libraries in this digital age}

Traditionally, libraries have focused on published information but new challenges also encompass non-explicitly published materials such as research data sets, interactive 
programs, complex visualizations, lab articles, diagrams, as well as web-based exchanges such as blogging. These materials have to be integrated into library resources in 'discovery tools'. This task requires new skills by librarians and demands they stay current on new and innovative approaches.

Information science instruction should occur throughout a Librarian's career and therefore be a part of their professional development. A variety of approaches, including online tutorials for basic skills, one-time classes, in-depth classes/workshops on strategies and tools for specific disciplines, and classes focused on information policy issues, such as intellectual property can be instituted by Information Science schools. Librarians also need to broaden their own concept of their role in the design of curriculum and provide outreach to faculty to help them understand how librarians can enhance the education of students.

Using new forms of technology such as mobile devices, You Tube, Internet of Things, 3D-printing etc. will enhance accessibility to library services and resources. The library's role in helping faculty and other researchers understand new ways to measure and evaluate research can be through the study of metrics.

\section{The future of library services}

With the gradual depletion of print astronomical journals and subscriptions to more and more e-journals, display space previously utilized for astronomy journals is being vacated. These 'maker spaces 'could be utilized for readers with Wi-Fi facility; providing e-book readers; meeting space for study and discussion; intellectual interactions with past and present students; or commons place for continuing education.

Change is an on-going evolution of library services. New technologies, new trends, and new ideas will emerge with new services. Are professional library skills useful in today's digital information world? Will libraries cease to exist? Will they become tourist attractions? Will they adapt to changing scenarios and shift focus to serve other related purposes?

\section{Concluding thoughts}

Notwithstanding all the issues, we need to remind ourselves that publishing is an agile, robust industry. Today the challenge is to discover, to create new ways of disseminating science research - through communication that's internet enabled and develop methods that will serve and justify a data-rich digital age. Intrinsic and inextricable to this very challenge is that libraries need to reinvent themselves and stay relevant by embracing the physical and the virtual, reinventing that defining feature of libraries as communities, as being more about "connections"than of "collections", and to stay committed to ensuring that knowledge is made accessible for the future - because "libraries are in the forever business".

\section{References}

Grothkopf, U. 2012, Organizations, People and Strategies in Astronomy I (OPSA I), 227-244 (Ed. A. Heck, https://www.eso.org/sci/libraries/articles/opsa_grothkopf.pdf)

Isaksson, E., Lagerstrom, J., Holl, A., \& Bawdekar, N. 2010, ASP Conference Series, 433 (Raman Research Institute Annual Report, 2014-2015)

Johnson, L., Adams Becker, S., Estrada, V., \& Freeman, A. 2015, NMC Horizon Report: 2015 Library Edition (Austin, Texas: The New Media Consortium.) 